\title{
Aspects of economic feasibility for the transport integrated use in favor of environmental security
}

\author{
Ruben Kazaryan ${ }^{1, *}$ \\ ${ }^{1}$ Moscow State University of Civil Engineering, Yaroslavskoe shosse, 26, Moscow, 129337, Russia
}

\begin{abstract}
The transport system in Russia and the transport support issues of national security differ completely from the Occident and other developed countries due to geostrategic and natural climatic conditions of our country. The integrated transport system, where in a sufficiently coherent manner used are the roads and railways, domestic water and air ways, pipeline transport, is more developed in the European area of the country. However, there is no assessment of economic feasibility for the integrated transport lines system. Firstly, assessment criteria for the transport support efficiency in favor of environmental security; secondly, mathematical economic models of various transport types integrated use in favor of environmental security; thirdly, economic feasibility methods for transport integrated use in favor of environmental security, that unavoidably leads to unreasonable transport operations using the existing rail and water ways at little distances, and increases their base cost by several times versus the transport by road. High dynamics of transport support for economic, demographic and environmental security within a market economy require the development of approach for the transport integrated use in favor of Russia national security. This article describes some practical recommendations for transport systems control bodies regarding the efficiency improvement of their use in favor of environmental security.
\end{abstract}

\section{Introduction}

To understand the matter of assessment for economic feasibility of integrated transport lines system it is necessary to make specific some terminology issues, which include the following items: "transport products quality control", "transport products quality control system", "efficiency of transport products quality control system".

Transport products quality control is the activities of control body officers focused on ensuring of meeting the requirements (standard technical documents, consumers) applicable to transport products.

Transport products quality control system is the set of elements required for timely and qualitative performance of works at the transport operations facilities. It includes the following: organizational structure of the body; rights, liabilities, authorities and responsibilities of the officers; procedure of production activity execution, processes of

\footnotetext{
* Corresponding author: r.kazarian@mail.ru
} 
subdivisions interaction against each other, and with the customers and suppliers, procedure of control and assessment for products and processes, material support, personnel training.

\section{Materials and methods}

Efficiency of transport products quality control system is the ability to implement purposes, for which achievement developed was this system; - performance measured by degree of purposes in hand implementation in the area of transport products quality control.

The approach for multi-criteria assessment of efficiency for environmental security quality systems is of interest to solve the task. The efficiency of transport support for environmental security seem to be evaluated applying the system of indices, ones of which may be the criteria, the other ones - the restrictions. For conception of grounding the system of efficiency indices proposed is the procedure to be implemented in 3 phases.

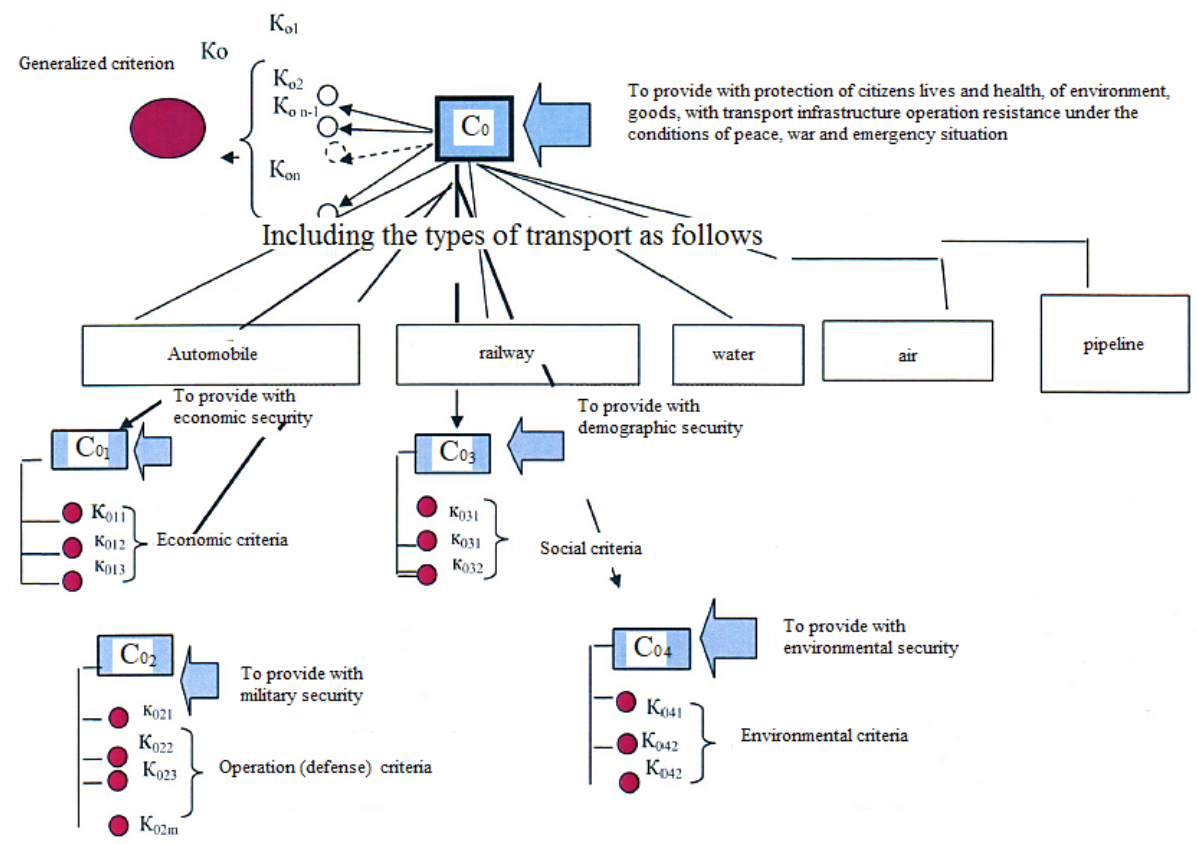

Fig. 1. Principle diagram of purposes decomposition and of efficiency criteria development (diagram "purposes-criteria").

$1^{\text {st }}$ phase - development of transport support technological purpose for environmental security. The construction (decomposition) of purposes system is given in Fig. 1.

$2^{\text {nd }}$ phase - development of transport support efficiency indices, criteria and restrictions; system approach for quality control purposes decomposition.

As the efficiency is the degree of purposes implementation, then it is required to define the purpose, for achievement of which developed was the control system, and to execute its decomposition. The example of purpose decomposition is given in Fig.2. Within the meaning of "efficiency" definition, it is reasonably to say about the efficiency of achievement of each separate purpose. Said another way, the efficiency of transport products quality control may be evaluated in whole, as well as the efficiency of tasks performance, e.g.: "To provide with meeting the requirements for transport products", "Transport processes quality control", etc. 


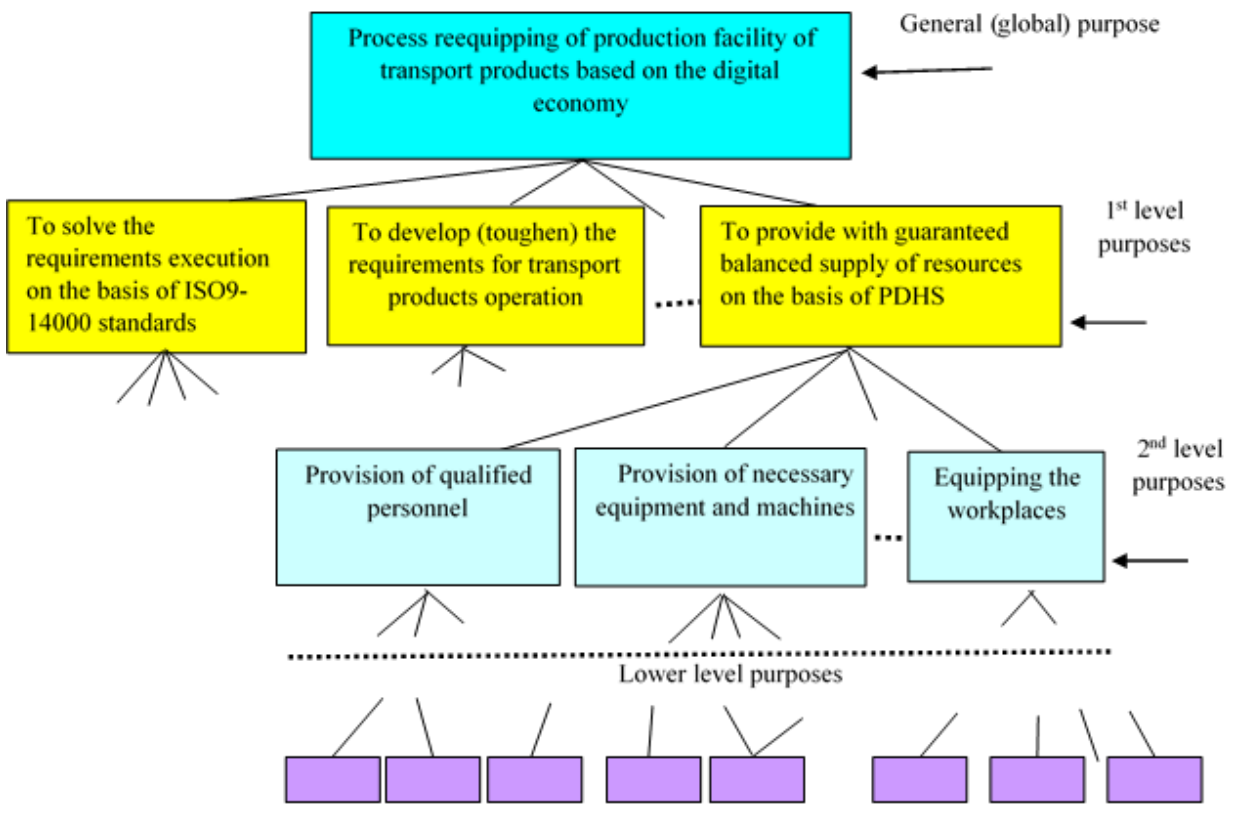

Fig. 2. Example of purposes decomposition for transport products quality control.

$3^{\mathrm{d}}$ phase. Identifying of efficiency indices of achievement for assessment of the procedure quality of transport products control system. As far as the purposes have various origins (production, economic, environmental, social, etc.), then it is inappropriate to reduce the efficiency only to economic one, as the efficiency may be the production one, economic, environmental, social, etc. The interaction of "purpose" and "efficiency" categories is given in Fig.3. The achievement of every purpose is evaluated using the system of indices (cost, labour costs, time, etc.). According to the theory of efficiency, it is a common practice to divide these indices in two groups: criteria and restrictions, to provide stringent requirements for efficiency of project developments, process and organizational solutions using the economic-mathematical methods of systemic-purposive approach modeling for assessment of quality systems elements control of transport production.

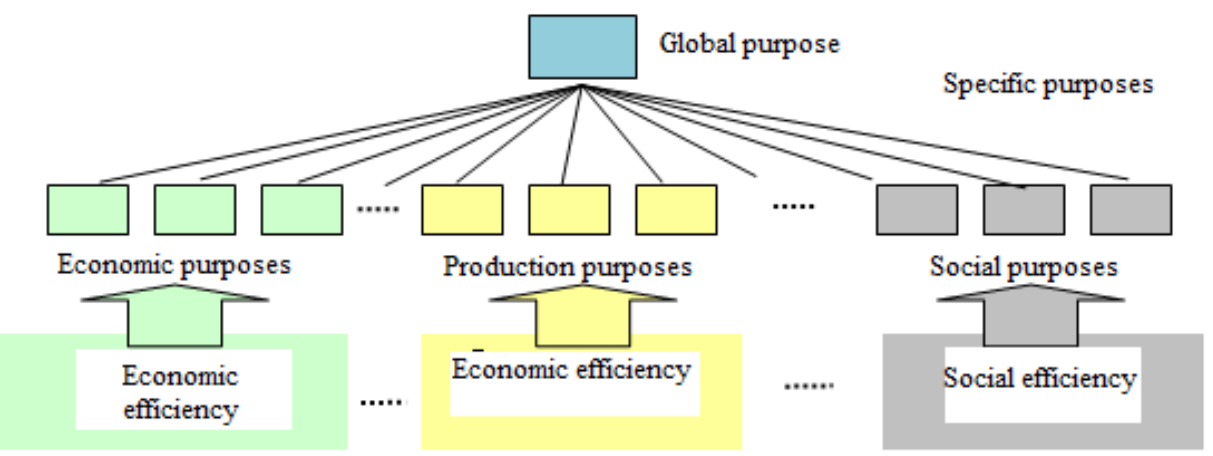

Fig. 3. Interaction of "purposes" - "efficiency" categories - the basis of environmental security.

At the present time the multicriteria of assessment of the abovementioned processes is one of essential tasks for environmental security of the present-day transport production. 


\section{Results}

Criteria identifying may be executed as follows:

Firstly, either as instructed by the manager or the criteria are established by the specific subdivision on the quality systems elements development based on the policy and purposes in the area of a transport company quality, with account of current tasks performance regarding the transport products manufacture, and the external factors (conditions), affecting to the quality control system functioning (works performance during the emergency recovery, occurrence of critical and accidental situations, etc.) and, depending on these factors, not only purposes may be changed, but the sum of processes contained in the system. As far as there are may be several criteria of efficiency assessment (the most standard situation), it is required to use the multicriteria assessment methods in assessment of quality control system efficiency. In this case, the method of multicriteria assessment of efficiency using the generalized criterion $K_{o}$, formed from several specific criteria $K i$ :

$$
K_{0}=\sum_{i=1}^{n} \alpha_{i} K_{i}^{n} \rightarrow \min
$$
$K_{i}$.

where $\alpha_{i}$ - weight of every $i$-criterion $K_{i} ; K_{i}^{n}-$ standardized value of specific criterion

Standardization is necessary to bring one-dimensional criteria to multidimensional ones during their summing.

Standardization is executed using the formula:

$$
K_{i}^{n}=\frac{K_{i f}}{K_{i}^{p r}}
$$

where $K_{i f}$ and $K_{i}^{p r}$ are actual and maximum (or standard) values of criterion as applicable.

Practically, there are common situations in which not all criteria have the same direction of optimization (i. e. all criteria tend either to minimum or to maximum). In this case the dependence of $K_{0}$ is divided in two parts: in one part aggregated are the minimized criteria, in other one - maximized criteria. If to specify the first group through $K_{i}(i=1,2, \ldots, m)$, and the second one through $\mathrm{K}_{\mathrm{j}}(\mathrm{j}=1,2, . ., 1)$, then there is the following formula of $\mathrm{K}_{\mathrm{o}}$ calculation:

$$
K_{0}=\sum_{i=1}^{m} \alpha_{i} K_{i}^{n}+\sum_{j=1}^{l} \alpha_{i} \frac{1}{K_{j}^{n}} \rightarrow \min
$$

To calculate the generalized coefficient of efficiency it is required to know the "weight" or significance of every specific $i$ - criterion $\alpha_{i}$.

The efficiency criteria are subjected to systemic economic-mathematical modeling during the development of adopted criteria system.

As a rule, specific criteria are formed by using two methods:

- $\quad$ expert - inquiry of experts - treatment of received data by mathematical statistics methods

- determination of compromise value $\alpha_{i}$;

- by the expert - by the single person making the decision.

Methodological approach of criteria and restrictions system with elements of economicmathematical modeling of assessment for economic efficiency of goods and passengers transport planning at the region territory is the basis of environmental security and is given as graphical model of transport routes in Fig. 4. 


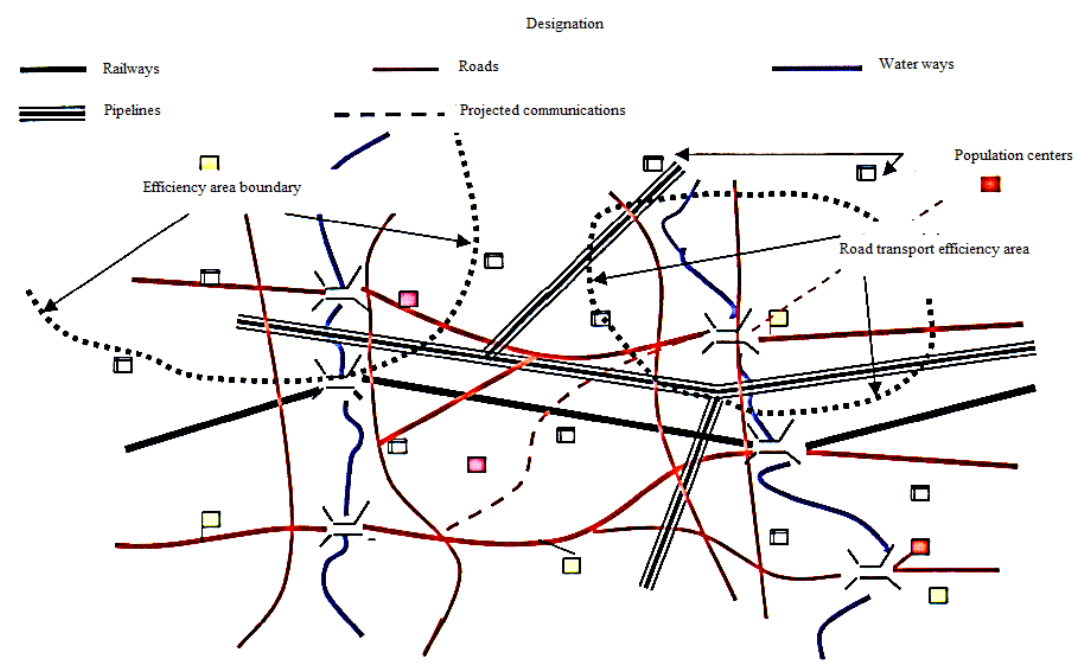

Fig. 4. Graphical model of the region transport lines system.

\section{Conclusions}

The considered systems of assessment of efficiency for general transport infrastructure use in whole, and for specific types of transport, may be considered as the basis of assessment of condition and efficiency increase of the various transport types integrated use in favor of environmental security provision. Herewith there emerged a necessity of monumental improvement for rules and regulations of integrated transport system comprehensive use on the basis of digital economy - new way of national development. Do this requires involving the lead teams of transport and construction HEIs (MGSU, MIIT, etc.), as well as NIU and transport systems control bodies.

Do this requires the major organizational and technical, administrative-and-managerial efforts of all governmental authorities involving the vast financial, material and labour resources.

\section{References}

1. B.A. Lyovin, R.R. Kazaryan, V.O. Chulkov, Infographics of anthropotechnical management. Vol.1 Infographic modeling in the mental activity philosophy in 3 volumes (2016)

2. B.A. Lyovin, R.R. Kazaryan, V.O. Chulkov, Infographics of anthropotechnical management. Vol.2 Conception of advanced development of anthropotechnical security of functioning and life quality in 3 volumes (2016)

3. B.A. Lyovin, R.R. Kazaryan, V.O. Chulkov, Infographics of anthropotechnical management. Vol.3 Anthropotechnical management as a means of provision of activities service Scientific publication. In 3 volumes (2016)

4. An. Mottaeva, Methodology of spatial distribution of enterprise structure of the region on the basis of development of transport infrastructure (St. Petersburg State University of service and economy, St. Petersburg, 2012)

5. R.R. Kazaryan, Science review, 11 (2016) 
6. R.R. Kazaryan, I.A. Bunkina, Natural and engineering science, 6(84) (2015)

7. An. Mottaeva, D. Rodionov, Spatial distribution of transport infrastructure as basis of development of enterprise structure of the region (Asterion, St. Petersburg, 2011)

8. R.R. Kazaryan, E.K. Muracheva, Natural and engineering science, 11 (2015)

9. R.R. Kazaryan, I.A. Bunkina, Science review, 23 (2015)

10. R.R. Kazaryan, Science review, 22 (2015)

11. R.R. Kazaryan, V.O. Chulkov, Science review, 24 (2015)

12. V.O. Chulkov, O.N. Kuzina, Control for investment-construction and housing-andmunicipal complexes: International collection of research papers, 410-426 (2010)

13. V.O. Chulkov, O.N. Kuzina, Current problems of housing and municipal services development in cities and population centers: International collection of research papers of the 9th International research and practice conference, 439-443 (2010)

14. As. Mottaeva, D. Knyazev, Economy and entrepreneurship 10, 626 (2016)

15. A.A. Volkov, V.O. Chulkov, G.O. Chulkov, R.R. Kazaryan, O.N. Kyzina, Advanced Materials Research 1065-1069, 2405-2408 (2015)

16. A.A. Volkov, V.O. Chulkov, G.O. Chulkov, R.R. Kazaryan, O.N. Kyzina, Advanced Materials Research 1065-1069, 2405-2408 (2015)

17. C. Gini, Statistics (Le Medi/Corrado Gini., Milano, 2010)

18. A.A. Lapidus, H.L. Saydaev, Construction technology and organization, 1 (2012) 